\title{
The RESEARCH AND COMPILATION OF CITY MAPS IN THE NATIONAL GEOMATICS ATLAS OF THE PEOPLE'S REPUBLIC OF CHINA
}

\author{
WANG Guizhi ${ }^{1} *$, WANG Donghua ${ }^{1}$, ZHOU Wen $^{2}$, CHEN Mian $^{3}$, ZHAO Tingting ${ }^{1}$ \\ ${ }^{1}$ National Geomatics Center of China, 100830 Beijing, China - wmj@ngcc.cn \\ ${ }^{2}$ Heilongjiang Administration Surveying, Mapping and Geoinformation, 150086 Haerbin, China \\ ${ }^{3}$ Chinese Academy of Surveying and Mapping, 100830 Beijing, China
}

Commission VI, WG VI/4

KEY WORDS: new century version of National Geomatics Atlas of the People's Republic of China, map visualization, map symbol, cartographic generalization, mapping scope, city map

\begin{abstract}
:
The research and compilation of new century version of the National Huge Atlas of the People's Republic of China is the special basic work project by Ministry of Science and Technology of the People's Republic of China. Among them, the research and compilation of the National Geomatics Atlas of the People's Republic of China is its main content. The National Geomatics Atlas of China consists of 4 groups of maps and place name index. The 4 groups of maps are separately nationwide thematic map group, provincial fundamental geographical map group, landcover map group and city map group. The city map group is an important component part of the National Geomatics Atlas of China and mainly shows the process of urbanization in China. This paper, aim at design and compilation of 39 city-wide maps, briefly introduces mapping area research and scale design, mapping technical route, content selection and cartographic generalization, symbol design and visualization of map, etc.
\end{abstract}

\section{INTRODUCTION}

The city map group is composed of three scales of macroscopic, meso - and micro - maps. It reflects the urban situation of China from three aspects of national survey, key area and single city. The city map group includes 4 city thematic maps of nationwide, 3 urban agglomeration maps of key area, 34 city maps of provincial capital-level and 5 city maps of specifically designated in the state plan.

Through the combination of multi-scale, it not only indicates the macroscopic view of the urban development, but also reflects the detailed content of the city. The specific contents are as follows:

\subsection{City Thematic Maps of Nationwide}

There are 4 city thematic maps of nationwide such as Chinese Cities, Urbanization in China, Famous Cities and Towns in China, Urban Agglomeration in China and its Strategic Distribution. These maps reflect the urban spatial distribution and the process of urbanization in our country from the macroscopic point of view, through the geographical location of the city, the size of the population, the size of the GDP, the historical and cultural evolution, the relationship, the development strategy and many other indicators

\subsection{Urban Agglomeration Maps of Key Area}

In order to reflect the characteristics of the development of the new era, 3 key areas with strong development momentum have been selected, including Metropolis Circle of Beijing, Tianjin and Hebei, Urban Agglomeration of Yangtze River Delta, Bay Area of Guangdong, Hong Kong and Macao. The three maps are shown in the form of island in the administrative region, and the drawing content does not have to be full of the entire map.

\subsection{City-wide Maps}

There are 39 city maps in total such as Beijing, Shanghai, Tianjin, Chongqing, Shijiazhuang, Taiyuan, Huhehaote, Shenyang, Changchun, Haerbin, Nanjing, Hangzhou, Hefei, Fuzhou, Nanchang, Jinan, Zhengzhou, Wuhan, Changsha, Guangzhou, Nanning, Haikou, Chengdu, Guiyang, Kunming, Lasha, Xian, Lanzhou, Xining, Yinchuan, Wulumuqi, Xianggang, Aomen, Taibei, Shenzhen, Xiamen, Ningbo, Qingdao, Dalian. This set of maps shows the most complete range and the most clear spatial pattern in the city map of China so far.

The lower 39 city maps in the third part are the subject content, so they are the objects discussed in this article. Their difficulty lies in the huge amount of work in drawing and complex mapping technology.

\section{RESEARCH OF MAPPING SCOPE AND DESIGN OF SCALE}

\subsection{Research of Mapping Scope}

This project originally designed and compiled a set of city maps which only included the main areas of cities. Later, after further research and analysis, it is considered that the mapping areas are too small to completely reflect the spatial layout and structural characteristics of the cities.

\footnotetext{
* Corresponding author
} 
Therefore, the scope of urban drawing is restudied, delimited and expanded. It not only covers all the blocks, but also makes a complete network of high grade roads. The main feature of the improved urban map is to express the urban skeleton and the large spatial layout through completely representing the high level road network and the neighborhood area. Selection of other elements and notes should be closely focused on the theme of the urban skeleton.

Besides, considering that the subway is an important manifestation of urban development, it should be expressed. However, the subway will interfere with the beauty and clarity of the main graph if it is placed in the main graph. Therefore, the urban subway line network is specifically expressed by illustration.

Take the city map of Nanjing as an example, the comparison on scopes and characteristics of original and new city maps are shown in figure 1 .

Obviously, the new city map is more scientific and reasonable, and it can show the characteristics of the city more completely.

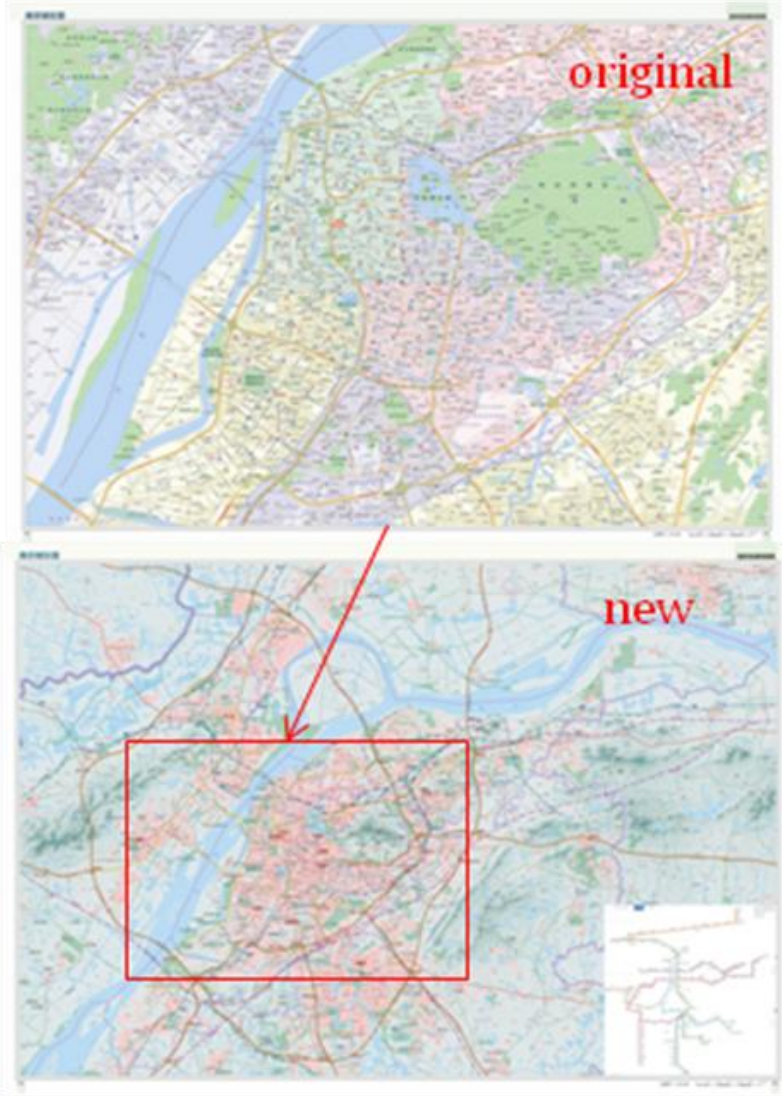

Figure 1. the comparison on scope and characteristic of original and new city map

\subsection{Design of Scale}

The new century version of the National Huge Atlas of the People's Republic of China will be published uniformly in quarto in the future. The National Geomatics Atlas of China will also be, that is the book size of $370 \mathrm{~mm} \times 520 \mathrm{~mm}$. An open page of the National Geomatics Atlas is folio and its core size is
$704 \mathrm{~mm} \times 480 \mathrm{~mm}$. The page gauge of the National Geomatics atlas is like the following figure 2 .
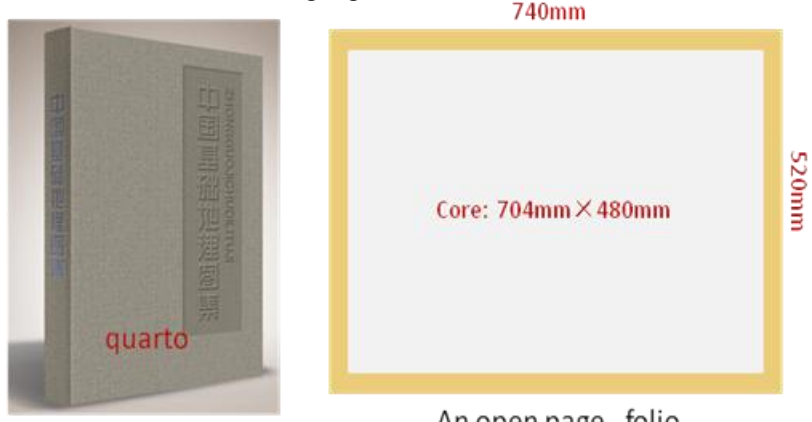

An open page, folio

Figure 2. the page gauge of the National Geomatics Atlas

The each of city maps is represented in an open page except for Hongkong and Macao, which are merged in an open page.

For making full use of paper pages, according to the size of the mapping scope, the map scale of each city map is designed. In total, 39 cities are classified as 6 kinds of scale, which are 1:120000, 1:100000, 1:80000, 1:60000, 1:50000 and 1:20000. The specific contents are summarized as follows in table 1 :

\begin{tabular}{|c|c|c|c|}
\hline ID & Scales & $\begin{array}{l}\text { Number } \\
\text { Of cities }\end{array}$ & Cities \\
\hline 1 & 1: 120000 & 3 & Beijing, Shanghai, Tianjin \\
\hline 2 & 1: 100000 & 6 & $\begin{array}{l}\text { Chongqing, Nanjing, } \\
\text { Wuhan, Guangzhou, } \\
\text { Chengdu, Dalian }\end{array}$ \\
\hline 3 & 1: 80000 & 10 & $\begin{array}{l}\text { Shenyang, Changchun, } \\
\text { Haerbin, Hangzhou, } \\
\text { Nanchang, Jinan, Kunming, } \\
\text { Xian, Shenzhen, Qingdao }\end{array}$ \\
\hline 4 & 1: 60000 & 15 & $\begin{array}{l}\text { Shijiazhuang, Taiyuan, } \\
\text { Huhehaote, Hefei, Fuzhou, } \\
\text { Zhengzhou, Changsha, } \\
\text { Nanning, Guiyang, Xining, } \\
\text { Yinchuan, Wulumuqi, } \\
\text { Taibei, Xiamen, Ningbo }\end{array}$ \\
\hline 5 & 1: 50000 & 3 & Haikou, Lasha, Lanzhou \\
\hline 6 & 1: 20000 & 2 & Xianggang+Aomen \\
\hline
\end{tabular}

Table 1. scale classification of city maps

\section{MAPPING TECHNICAL ROUTE}

The general idea of producing city maps is configuring the map symbol after setting up the database. That is, we use all kinds of relevant data firstly to produce the vector line data of city map. Then, we automatically configure map symbols based on database and compile map products quickly. The specific technical methods are as follows:

First of all, based on the national fundamental geographic information database of China, research and delimit the scope 
of the city map, extract and edit the urban framework elements, form a sketch of a city map.

Then, making full use of all kinds of publicly available urban map data such as network map, urban tourism map, image data, printing paper map provided by the Provincial Bureau of Surveying and Mapping, supplement and update map elements, edit and make the city line maps.

Finally, design the symbol system of city map, the city line maps are symbolized. At the same time, superimpose a city line map on hill-shading map, form a beautiful city map.

The specific technical routes and methods are as following figure 3 .

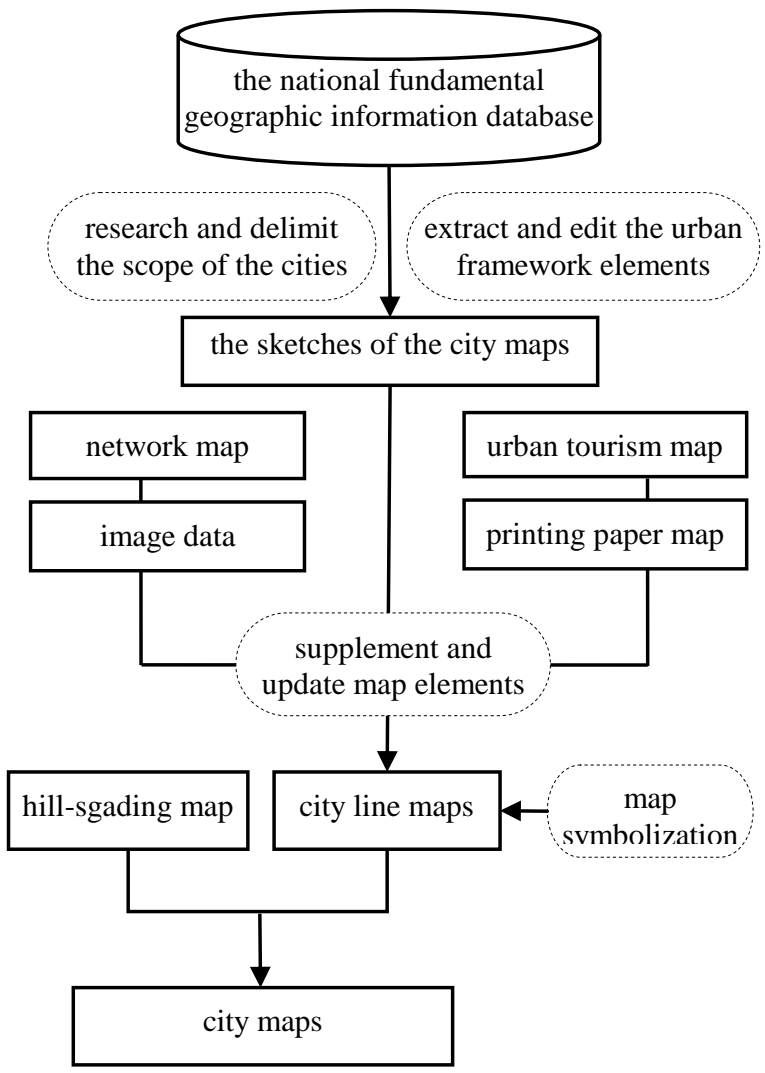

Figure 3. Technical process and method of compiling city maps

\section{CONTENT SELECTION AND CARTOGRAPHIC GENERALIZATION}

The city map mainly represents the basic geographic information, such as boundary, residential area and ancillary facilities, blocks and streets, roads and ancillary facilities, water system, independent objects, place names and notes. The various elements selection and cartographic generalization are as follows:

Select and extract the urban framework elements from the national fundamental geographic information database of China.

Update and supplement the spatial geographical elements based on image maps or scanned paper maps, such as urban roads, blocks, residential areas, rivers, names, etc..
Referring to the network maps of Gaode, Baidu and Google, the road skeleton of each city is constructed, in order to connect the high grade road network. The railway in the city does not express the ring road, its shape is simplified.

Edit and deal with the shape of residential neighborhoods, The main block of the continuous piece should be fully expressed, so that the spatial structure of the block should be completely. Township residents outside main street was completely expressed. The village level residents are properly chosen.

Referring to web maps and other paper maps, check and supplement the location and name of public facilities such as roads, parks, tourist attractions, large conference centers, sports venues and theaters.

Express the name of the roads as much as possible. The names of the administrative grade name are expressed from provincial government, municipal government and district government, until subdistrict office. Select the names and notes in accordance with the priority of street names, government departments, large public facilities, universities, hospitals, and residential areas.

The green space in the city is to be expressed. In order to make the large area of the scenic green space is not empty, appropriately supplement the paths inside scenic area referring to the city paper map. About the green spaces in the suburbs. use the shading map to reflect the surrounding green vegetation and create a picturesque scenery environment.

\section{SYMBOL DESIGN AND VISUALIZATION OF MAP}

In order to make the city maps beautiful, highlight the theme and easy to read, the research of map visualization and the design of symbols are carried out. All kinds of elements are designed hierarchically and classified. All the elements in the city maps are summed up into 40 categories and design symbols, according to categories.

In accordance with the design requirements, establish the symbol library system of city maps. The illustrations are shown in Figure 4.

\begin{tabular}{|c|c|c|c|c|}
\hline$\star$ & 省级和政中心 & . & k & 场 \\
\hline$\star$ & 地级原政中心 & + & 徼口、酖 & 头 \\
\hline - & 县留行政中心 & - & 立交桥、交通板组、互 & \\
\hline . & 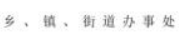 & $\ldots$ & 笛、自治区、直转光 & \\
\hline . & H & -....... & 物 别 行 政 区 & 䍙 \\
\hline . & 政 府 比关 & & 地 & 界 \\
\hline . & 经济开发区管委会 & & 悬 & 界 \\
\hline$=$ & 学 & 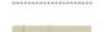 & 城 & 䏴 \\
\hline ○ & 医 & & 娚 区 及 道 & 路 \\
\hline$=$ & 图节的 & Nos & 高失极车 & 站 \\
\hline & 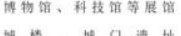 & 果_.A4 & 纪路 及 & 站 \\
\hline$=$ & 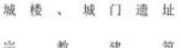 & 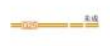 & 高速路及其能 & 吾 \\
\hline$n$ & 崇教建 算 & _.4 & 块 連 路、环 & 路 \\
\hline - & 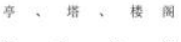 & 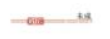 & 国道及其楸 & 号 \\
\hline$\cdot$ & 体首场销 & 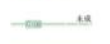 & 等道及其的 & 묵 \\
\hline 1 & 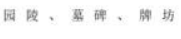 & $\longrightarrow$ & 其华 道 & 路 \\
\hline 1 & 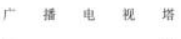 & .4 & $\mp$ & 道 \\
\hline r & kJ & + & 次 & 道 \\
\hline for & 山 & & 支 & 栈 \\
\hline 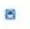 & * & 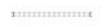 & 献 & 道 \\
\hline
\end{tabular}

Figure 4. symbol library system of city maps 
It can be seen from the above symbol system that point features use pictographic symbols as much as possible and the height class roads are most prominent such as highways, expressway and loops. It is necessary to separate the level and take into account the coordination of the overall color. The first level shows the high grade road frame, the important place name note and the block outline. The second level shows the inner structure of block, the low grade road, the water system, the green space and so on. The bottom is the hill-shading map as background.

\section{CONCLUSION}

The 39 city maps in the National Geomatics Atlas of China are different from the traditional city maps. On the mapping area, they are larger than the traditional city maps and cover the entire urban area and the main road frame. The main feature of these city maps is to highlight the city skeleton. The content selection is also closely related to the theme.

The drawing of city maps comprehensively use the national fundamental geographic information database, navigation maps, city map products, network maps, satellite images, DEM, etc. Draw block outline based on the national fundamental geographic information database. Extract road frame from navigation maps. Build road frame reference to network map. Supplement the place name note according to the city map product. Update the city maps with the latest image data and other new materials, the up-to-date reached 2016-2017. Product hill-shading map using DEM data as the base map.

The city maps in the National Geomatics Atlas of China mainly represent relative stable content such as blocks, roads network, large public facilities, government sectors, park, scenic spots, urban green space, names and annotations and so on. Briefly represent culture, sports, health and so on. Hardly represent the entities such as enterprises, institutions, business, etc.. To create a picturesque scenery environment, represent the hill-shading map outside the main urbans. In the process of mapping, pay attention to the relationship and consistency of the elements.

This is the most complete set of urban maps to date, including all the provincial capital cities and the planned single cities. Moreover, the city maps represent the largest urban scope, the most complete spatial pattern and the most complete content. It can be a good reference for leader going out, urban research, leader decision and so on.

\section{ACKNOWLEDGEMENTS}

I would like to express my heartfelt gratitude to Deputy Director Wang Donghua of NGCC, for his constant encouragement and guidance. I am also greatly indebted to the project team and my colleagues, who have supported and helped me a lot in research and implementation of the project in the past few years. Without their close cooperation and collaboration, this thesis could not have reached its present form.

\section{REFERENCES}

National Geomatics Center of China, the editorial department of National Geomatics Atlas, 2015. the Overall design scheme of new century version of the National Geomatics Atlas of the People's Republic of China.
WANG Guizhi, WANG Donghua, ZHOU Wen, ZHU Xiuli, The Studying of the National General Atlas of China, the 28th International Cartographic Conference, 2017.7.

LIU Jianjun, Construction and Update of the National Fundamental Geographic Information Database [J]. Bulletin of Surveying and Mapping, 2015.10, Page(s):1-3.

Map Publishing House of China, Version 2, January, 2011. "The Atlas of China "

WANG Donghua, SHANG Yaoling, LIU Jianjun, Technical Discussion of Database-driven topographic fast mapping [J], Geomatics World, 2012.2, Page(s):6-9.

WANG Guizhi, The Design and Product of National 1:1000000 Cartographic Data of Topographic Map, DOI: 10.1109/Geoinformatics.2015.7378691, Page(s):1-5, IEEE Conference Publications.

Kramers E, Interaction with Maps on the Internet — A User Centred Design Approach for The Atlas of Canada[J], Cartographic Journal, 2008.45(2), Page(s):98-107。

HAN Jiafu, The Map Visualization Design Oriented Atlas Compiling --- Take Population and Environmental Change Atlas of the People's Republic of China for example [J], Journal of Earth Information Science, 2010.12 (6), Page(s): 777-783.

LIAO Ke, The Milestone of Chinese Modern Cartography Development --- Characteristics and Innovation of China's National Atlas [J], Geography Scientific Progress, 2001.20 (03), Page(s): 200-207. 